\title{
AVALIAÇÃO DE SISTEMAS DE TELHADOS VERDES: ANÁLISE TÉRMICA EM DIFERENTES SISTEMAS CULTIVADOS COM CALLISIA REPENS
}

EVALUATION OF GREEN ROOF SYSTEMS: THERMAL ANALYSIS

IN DIFFERENT SYSTEMS CULTIVATED WITH CALISSIA REPENS

\section{Gustavo de Castro Carvalho}

Mestre em Ciências Ambientais pelo Instituto de Ciência e Tecnologia, Universidade Estadual Paulista "Júlio de Mesquita Filho" (UNESP) - Sorocaba (SP), Brasil.

\section{Paulo Sérgio Tonello (it)}

Físico, Doutor em Química pelo Instituto de Química UNESP -Araraquara, Professor do Instituto de Ciência e Tecnologia UNESP - Sorocaba (SP), Brasil.

\section{Jarbas Honorio} de Miranda

Doutor em Irrigação e Drenagem pela Escola Superior de Agricultura "Luiz de Queiroz" (ESALQ), Universidade de São Paulo (USP) Piracicaba (SP), Brasil.

\section{Endereço para correspondência:} Gustavo de Castro Carvalho Rua Antônio Festa, 33 - Jardim Pagliato - CEP 18046-176Sorocaba (SP), Brasil-E-mail: gcarvalhopaisagismo@hotmail.com

Recebido em: 24/05/2018

Aceito em: 09/11/2018
RESUMO

A crescente urbanização faz com que problemas ambientais se tornem mais frequentes; com isso, alternativas como o uso de telhados verdes mostramse importantes para a melhoria ambiental dos centros urbanos. $O$ presente trabalho buscou avaliar a temperatura em protótipos com diferentes sistemas de telhados verdes comerciais (Sistemas MacDrain, Modular e FLAT) cultivados com Callisia repens, para quantificar a melhoria em relação ao conforto térmico que esses proporcionam, comparando-os entre si e com um protótipo testemunha. Os resultados mostraram que, em horários com temperaturas elevadas, os sistemas conseguem atenuar a radiação solar, diminuindo a transferência de calor do meio externo para o compartimento instalado abaixo dos protótipos. Já em temperaturas amenas, como o período noturno, eles funcionam mantendo o calor absorvido durante o dia no compartimento abaixo, isolando a perda de calor. Realizando-se análises estatísticas, o protótipo testemunha apresentou diferença significativa, em relação aos demais sistemas, mostrando o potencial de telhados verdes no isolamento térmico. .

Palavras-chave: telhados verdes; conforto térmico; transferência de calor; isolamento térmico.

\section{ABSTRACT}

Increasing urbanization causes environmental problems to become more frequent and, therefore, alternatives such as the use of green roofs are important in the environmental improvement of urban centers. The present article has evaluated the temperature in different green roof systems prototypes (Systems: MacDrain, Modular and FLAT) cultivated with Callisia repens, to quantify the improvement related to the thermal comfort that these systems provide, comparing them with each other and with a control system. The results showed that the systems are able to attenuate the solar radiation with higher temperatures, reducing the transfer of heat from the external environment to the compartment below the prototypes. On the other hand, at night, normally with mild temperatures, the systems work by keeping the heat absorbed during the day in the compartment below, isolating the loss of heat. Statistical analysis has been made and the control prototype presented a significant difference in relation to other systems, showing the potential of green roofs in thermal insulation.

Keywords: green roof; thermal comfort; heat transfer; thermal insulation. 


\section{INTRODUÇÃO}

A urbanização mundial é contínua e crescente, os investimentos são limitados e a infraestrutura é obsoleta. Como consequência, tem-se a necessidade de desenvolvimento de estratégias inovadoras e abrangentes, as quais permitam administrar mais eficazmente as mudanças demográficas e estruturais (LEHMANN \& CROCKER, 2013).

O aumento global da população humana e a mudança de uma economia agrícola para outros tipos de economia de mercado têm provocado nas cidades uma expansão rápida e descontrolada (PRAMANIK \& STATHAKIS, 2016). Nesse cenário, o crescimento desenfreado na construção civil faz com que haja diminuição significativa de espaços destinados às áreas verdes, trazendo aos centros urbanos problemas relacionados a essa falta de vegetação, como inundações, ilhas de calor e poluição (BEZERRA et al., 2013; BARROS \& LOMBARDO, 2016). De acordo com Lima e Garcez (2017), os espaços verdes são indispensáveis à construção da estrutura da cidade e à integração dos espaços de convivência, de práticas de atividades físicas e lazer.

Para que seja possível solucionar as adversidades provenientes do desenvolvimento e da expansão urbana e alcançar uma convivência harmônica entre o homem e o meio ambiente, é imprescindível impedir o avanço das alterações já existentes, além de otimizar os pequenos espaços urbanos disponíveis, priorizando nestes a preservação ambiental, pois a presença de vegetação em ambientes urbanos aumenta a sensação de bem-estar da população e provoca nos indivíduos maior sentimento de pertencimento ao local.

Alternativas como coberturas vegetais, jardins verticais, calçadas ecológicas, jardins filtrantes e arborização urbana, além de melhorarem o aspecto visual, podem ser utilizados para gestão ambiental, uma vez que contribuem para a melhoria da qualidade ambiental. O paisagismo, apesar de essencialmente estar relacionado à estética, pode contribuir para elevação da umidade, diminuição da erosão e das ilhas de calor, bem como melhora na drenagem da água e na atração da avifauna (GENGO \& HENKES, 2012).

Para Sutton (2015), uma das formas de reinserção da natureza às cidades é a utilização de telhados verdes, uma vez que as condições urbanas se encontram limi- tadas, pois há somente pequenos espaços disponíveis para a vegetação.

O emprego de coberturas vegetais em edificações ocorre há muito tempo com o principal objetivo de melhorar o conforto térmico das construções por meio da redução da temperatura (OLIVEIRA, 2009). Niachou et al. (2001) ressaltam que o plantio em telhados, além de contribuir para o conforto térmico, também aumenta ou restitui a área urbana vegetada, reduzindo os efeitos relacionados às "ilhas de calor". De acordo com Santamouris (2014), a aplicação em larga escala de teIhados verdes pode reduzir de 0,3 a $3,0^{\circ} \mathrm{C}$ a temperatura ambiente. Além disso, esse tipo de construção possibilita a criação de jardins e espaços de contemplação e convivência antes inexistentes (RANGEL et al., 2015).

A utilização de telhados verdes em centros urbanos produz benefícios estéticos, sociais, terapêuticos e de lazer, uma vez que suaviza a paisagem por meio do aumento das áreas verdes. Também proporciona benefícios ambientais, como aumento na drenagem de águas superficiais, contribuindo para a diminuição de enchentes (ALAMY FILHO et al., 2016); permite a coleta e o armazenamento de águas pluviais, influenciando diretamente a economia de água tratada (TEIXEIRA et al., 2017); atua na absorção de ruídos das cidades, reduzindo a poluição acústica (YANG et al., 2012); promove redução nas variações de temperaturas entre ambientes, reduzindo o gasto de energia com o condicionamento de ar (SANTAMOURIS, 2014) e aumentando a eficiência energética dos edifícios (HASHEMI et al., 2015; GALLARDO et al., 2018).

Os telhados verdes são formados por vários componentes: vegetação, substrato, manta filtrante, camada de drenagem e impermeabilização, tendo cada componente um papel bem definido a ser desempenhado no sistema projetado para o local em que será instalado (VIJAYARAGHAVAN; JOSHI, 2015).

Em estudo com coberturas vegetais em Hong Kong, constatou-se que o principal benefício com a implantação desses sistemas foi o valor estético visual das edificações, mas fatores como qualidade do ar, redução das ilhas de calor e isolamento térmico também foram considerados. Verificou-se que o tipo de vegetação uti- 
lizada e a profundidade do solo são fatores determinantes no desempenho térmico (TAM et al., 2016).

As características estruturais das coberturas vegetais aumentam a capacidade de isolamento térmico pelo telhado e a água armazenada nessas estruturas também contribui nesse sentido (VIJAYARAGHAVAN, 2016). O uso de plantas com o maior adensamento possível é desejável no estabelecimento de um telhado ecológico, pois, com maior e mais densa cobertura vegetal sobre uma superfície, ocorre maior retenção de energia radiante. Aspectos como o sombreamento, melhor isolamento contra as radiações solares, promovido pela vegetação e pelo substrato, são responsáveis pela melhoria do desempenho térmico nas edificações (SAADATIAN et al., 2013). Em testes com coberturas vegetais de diferentes adensamentos realizados por Wong et al. (2003), as coberturas com vegetações mais esparsas apresentaram valores de temperaturas mais elevadas do que aquelas que usaram vegetações mais adensadas.

Uma cobertura vegetal extensiva em Singapura foi analisada antes da instalação da vegetação e após oito meses, com a vegetação já estabelecida. Os resultados indicaram que cerca de $60 \%$ do fluxo de calor foi retido com a instalação do telhado verde, assim como índices de ofuscamento, medidos no entorno do local no qual foi instalado o sistema e causados pela laje nua, também sofreram redução (HIEN et al., 2007). Dessa mesma forma, Onmura et al. (2001) determinou diferenças de $30^{\circ} \mathrm{C}$ de uma laje coberta com vegetação em relação à outra laje nua, apesar de terem sido expostas a mesma temperatura ambiente no verão do Japão.
Em relação ao aspecto ecológico, o uso de espécies frutíferas e/ou nativas proporciona maior diversidade da fauna nas cidades, além de servir como porta de entrada para o recebimento de uma grande variedade de pássaros e insetos. Tecnologias como o telhado verde são ótimas oportunidades para a flora e fauna criarem novos habitats (MINKS, 2013).

A decisão pela instalação de um telhado verde passa pela escolha de um dos diferentes sistemas de montagens oferecidos no mercado. Esses, por sua vez, são escolhidos levando-se em consideração, principalmente, os fatores estruturais da edificação, como a inclinação da laje e o esforço ao qual será submetida. Uma escolha baseada no conforto térmico e na redução energética não tem sido explorada, pois, apesar do longo tempo de uso dessa tecnologia, não existem informações comparativas sobre o potencial redutor térmico dos principais sistemas comerciais utilizados no Brasil. Informações dessa natureza permitiriam a escolha do sistema de telhado verde que melhor se adequasse às necessidades energéticas do ambiente, bem como apontariam a eventual adaptação do projeto arquitetônico e estrutural.

Pelo exposto, a proposta deste trabalho foi analisar a eficiência térmica de três diferentes sistemas de telhados verdes comerciais (FLAT, MacDrain e Modular) cultivados com a espécie, do tipo suculenta, $\mathrm{Cal}$ lisia repens, comumente utilizada nessas coberturas. A eficiência térmica foi avaliada por meio de sensores de temperatura dispostos perpendicularmente à superfície vegetal dos sistemas para verificação da atenuação da temperatura em diferentes pontos. Os resultados dos três modelos foram comparados aos de um protótipo apenas impermeabilizado, representando uma laje comum, sem cobertura vegetal.

\section{MATERIAIS E MÉTODOS}

\section{Caracterização da área experimental}

O projeto foi desenvolvido na cidade de Sorocaba, São Paulo, situada nas seguintes coordenadas geográficas: -23.5062 (latitude); -47.4559 (longitude); $23^{\circ} 30^{\prime} 22^{\prime \prime}$ sul e $47^{\circ} 27^{\prime} 21^{\prime \prime}$, com altitude de 562 $\mathrm{m}$, temperatura média anual de $19,4^{\circ} \mathrm{C}$ e índice plu- viométrico médio anual de $1.224 \mathrm{~mm}$, resultando na classificação climática de Köppen-Geiger em Cfa, com clima subtropical úmido, caracterizada por chuvas no verão e inverno seco (CLIMA SOROCABA; INFORMAÇÕES SOROCABA, 2018). 


\section{Montagem dos protótipos}

Para a instalação dos sistemas, foram estudados os materiais mais utilizados atualmente no âmbito de coberturas vegetais.

\section{Sistemas utilizados}

A empresa especializada em telhados verdes forneceu todos os materiais utilizados para a montagem dos protótipos, como as diferentes estruturas empregadas nos modelos, o substrato, o sistema de irrigação, além de toda a vegetação necessária.

Com base nas informações da empresa, todos os sistemas utilizados estão descritos a seguir.

Para o Sistema FLAT, o local de instalação não deve possuir inclinação superior a $5 \%$, sendo o mais adequado para lajes e coberturas planas, as quais possuem entre 2 e $5 \%$ de inclinação. Superfícies que apresentam inclinação inferior a $2 \%$ devem utilizar sistemas especiais para evitar o acúmulo de água, garantindo, assim, uma boa drenagem do jardim.

Sobre o protótipo foram instaladas placas de PVC $(0,50 \times 0,50 \times 0,10 \mathrm{~m})$, as quais são utilizadas para suportar o sistema e armazenar a água, diminuindo a necessidade de sistema de irrigação no jardim. O filtro de drenagem foi inserido sobre o Sistema FLAT, de forma a permitir a drenagem e fazer com que ela ocorra de forma correta, sem que haja o acúmulo de água em alguns pontos do sistema, além de reduzir o carreamento de partículas sólidas do sistema e manter a circulação de ar necessária para o bom desenvolvimento radicular. O substrato foi inserido sobre a manta de drenagem. Somente após a instalação dessas camadas fez-se o plantio da vegetação.

Nesse sistema é possível a elaboração de um projeto de paisagismo mais completo, com diferentes alturas

\section{Estrutura}

Para a montagem das caixas que receberam os sistemas, utilizou-se o compensado naval: material composto por três lâminas prensadas de madeira e resina fenol-formaldeído. A vantagem de sua utilização deve-se ao ma-
Os sistemas comerciais de coberturas vegetais escolhidos para as avaliações foram: FLAT, Modular e MacDrain, além da testemunha, que é apenas um protótipo impermeabilizado, sem o telhado verde, totalizando dessa forma, quatro protótipos.

e volumes de substrato. A camada de substrato, que pode variar em altura, possibilita o desenvolvimento de vegetação de grande porte. Dessa forma, arbustos e árvores podem se estabelecer nessas coberturas vegetais. O cálculo estrutural deve ser realizado imprescindivelmente, para que seja analisado o peso que poderá ser suportado pelo sistema.

O Sistema Modular pode ser utilizado em locais com inclinações superiores, em comparação às possíveis para o Sistema FLAT, sendo ideal para inclinações entre 5 e $35 \%$, uma vez que se utiliza uma camada de apenas $5 \mathrm{~cm}$ de substrato. Inclinações superiores a $30 \%$ devem conter sistemas de travamento especialmente desenhados para evitar o deslizamento do sistema de cultivo.

Esse sistema é composto por módulos $(0,50 \times 0,50 \times$ $0,075 \mathrm{~cm}$ ) que se encaixam e formam a cobertura vegetal. Cada módulo possui o filtro de drenagem instalado e pronto para receber o substrato e a vegetação.

Por apresentar limite máximo de $5 \mathrm{~cm}$ de profundidade para o substrato, nesse sistema, a vegetação utilizada deve ser escolhida de acordo com o desenvolvimento das raízes, uma vez que espécies que necessitam de grandes profundidades terão seu desenvolvimento e sua sustentação prejudicados. A utilização de plantas herbáceas é comumente vista nesse tipo de cobertura, já que possuem raízes pouco profundas.

No Sistema MacDrain utiliza-se apenas a manta MacDrain - uma camada de drenagem - com o substrato e a vegetação sobre o sistema.

terial ser à prova d'água, o que permite a exposição ao tempo, aliando versatilidade e grande resistência.

O compensado naval foi adquirido na forma de peças inteiriças, as quais foram cortadas utilizando-se uma 
cortadora a laser, o que permitiu a realização de cortes com encaixes exatos. Com a junção dos encaixes, aliada à utilização de parafusos para a melhor fixação, formou-se a caixa que, posteriormente, foi tratada com o sistema de impermeabilização e recebeu os sistemas de telhados verdes.

A impermeabilização foi realizada pela empresa Omnitrade, a qual utilizou uma manta de PVC, que possui durabilidade em torno de 10 a 15 anos, leveza e estanqueidade, quando comparada à utilização de outros materiais, como a manta asfáltica.

As caixas de madeira com os sistemas instalados foram dispostas sobre bancadas de alumínio, inclinadas $\left(3^{\circ}\right)$, com sensores de temperatura alocados acima e abaixo do sistema.

Para que não houvesse influência de ventos e outras variações climatológicas, foram instaladas caixas espessas de isopor tipo P3 (Figura 1). Placas espessas de isopor foram utilizadas para montagem das caixas, para isolar eficientemente o sistema. Entre a caixa de isopor e a caixa de madeira, aplicou-se silicone, com a finalidade de diminuir ainda mais as influências externas que o sistema poderia sofrer. Na Figura 2 está representado o protótipo em vista superior.

As dimensões dos quatro protótipos são iguais, sendo que a caixa de compensado naval tem $1,10 \mathrm{~m}$ de comprimento, 0,70 $\mathrm{m}$ de largura e 0,20 $\mathrm{m}$ de altura, com a espessura de $5 \mathrm{~cm}$ em todas as peças utilizadas para formar a caixa. Além disso, a manta de PVC utilizada para impermeabilização tem $1 \mathrm{~cm}$ de espessura. Já a caixa de isopor acoplada a estrutura de madeira tem as mesmas dimensões em comprimento e largura, e $0,60 \mathrm{~m}$ de altura, com espessura de $10 \mathrm{~cm}$ em todas as peças.

Com base na Lei de Fourier, Equação 1, que estabelece o fluxo de calor entre dois pontos (RODRIGUES et al., 2009), foi calculado o valor da condução de calor para o isopor e o tijolo de alvenaria, que possuem condutividade térmica de 0,035 e 0,658 (KREITH et al., 2014; MOAVENI, 2016), demonstrando eficiência na redução da condução do calor do isopor utilizado para isolar o sensor abaixo das variações climatológicas, quando comparado a uma construção que utiliza tijolo.

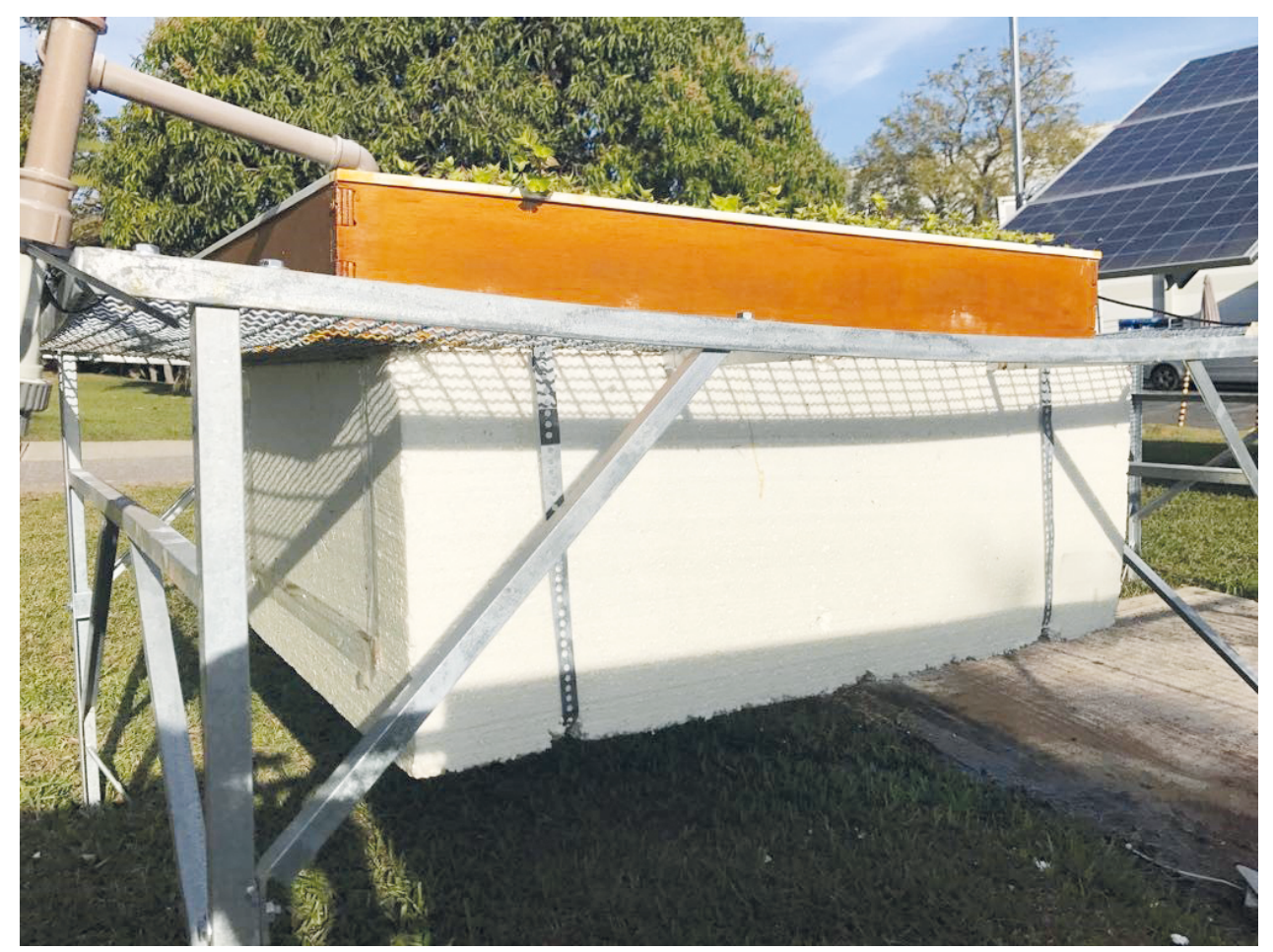

Figura 1 - Protótipo finalizado: caixa de isopor acoplada à caixa de madeira. 
$q_{k}=-k A \frac{d T}{d X}$

Em que:

$q_{\mathrm{k}}=$ taxa de transferência de calor;

$\mathrm{T}(\mathrm{x})=$ temperatura local;

$\mathrm{x}=$ distância na direção do fluxo de calor;

$\mathrm{k}=$ condutividade térmica, que, de forma geral, varia com a temperatura.

Conforme a NBR 16401 (ABNT, 2008), os limites para conforto térmico são temperaturas entre $22,5-26^{\circ} \mathrm{C}$ no verão; sendo assim, foi utilizado como base para cálculo o valor de $24,25^{\circ} \mathrm{C}$.

\section{Espécie vegetal}

A espécie utilizada no projeto, Callisia repens (Jacq.) L., pertence à família botânica Commelinaceae, que possui ampla distribuição em países tropicais, com 60 espécies descritas no Brasil (SOUZA \& LORENZI, 2005).
De acordo com a estação climatológica instalada na faculdade onde os protótipos foram analisados, o valor máximo de temperatura registrado em 2017 foi de 41,2 ${ }^{\circ} \mathrm{C}$, em 26 de janeiro de 2017.

Sendo assim, foram utilizados o valor de temperatura máxima registrada para Sorocaba no verão e o valor médio para o conforto térmico, segundo a NBR 16401/08, para cálculo da condução do calor.

Em relação ao tijolo de alvenaria, o isopor reduziu cerca de $95 \%$ a condução do calor, demonstrando eficiência no isolamento dos sensores abaixo dos protótipos instalados.

A Callisia repens é considerada uma planta suculenta. Conhecida popularmente como dinheiro-em-penca, apresenta porte de 10 a $15 \mathrm{~cm}$ quando está em pleno desenvolvimento, sendo considerada uma

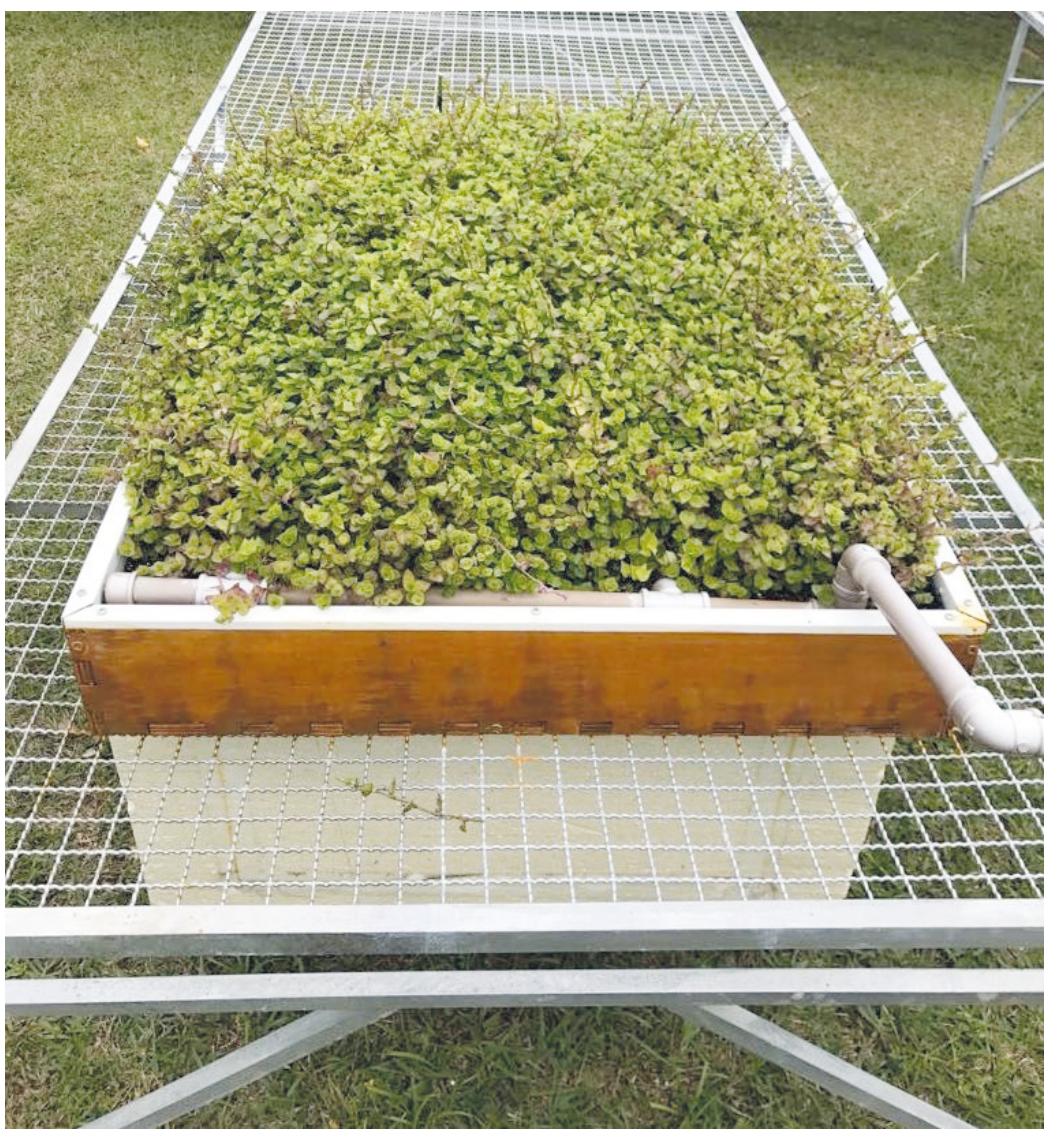

Figura 2 - Vista superior do protótipo finalizado. 
espécie herbácea muito ramificada e perene. As foIhas apresentam aspecto brilhante, encerado, sendo ovais acuminadas e de cor verde-claro. As flores são brancas e pequenas, sem caráter ornamental. São plantas que não resistem a pisoteio e são consideradas excelente espécie para cobertura vegetal (STUMPF, 2017).

Berghage et al. (2007) identificaram que as plantas suculentas transferem rapidamente a água consumi-

\section{Substrato e sistema de irrigação}

O substrato utilizado é composto por turfa de Sphagnum, vermiculita expandida e calcário dolomítico, que proporcionam maior aeração, aumentando, assim, o sistema radicular das plantas cultivadas, além de gesso agrícola e fertilizante NPK, que fornecem os nutrientes necessários para o desenvolvimento das plantas, sem necessidade inicial de adubação. $\mathrm{O}$ pH do material é por volta de 5,5 e a densidade, de $145 \mathrm{~kg} / \mathrm{m}^{3}$, além de apresentar $55 \%$ de capacidade de retenção de água.

O sistema de irrigação utilizado é do tipo gotejamento, formado por duas linhas de irrigação com $1 \mathrm{~m}$ de extensão cada, dispostas igualmente nos três protótipos. Ao longo da tubulação foram feitas pequenas perfura-

\section{Coleta de dados térmicos}

Após a finalização das montagens e instalação dos protótipos, foi realizada, durante o período de agosto a novembro de 2017 , a coleta dos dados de temperatura, os quais foram analisados para cada um dos diferentes sistemas.

Foram instalados oito sensores, sendo dois em cada protótipo. Os sensores dispostos sobre as caixas de madeira foram utilizados para a coleta de dados de temperatura externa. Abaixo das caixas, isoladas pelo compartimento de isopor, foram instalados sensores que permitiram a coleta dos dados de temperatura após a incidência dos raios solares no siste-

\section{Análises de conforto térmico}

Os dados da temperatura interna, coletados pelos sensores em dois diferentes horários, às $13 \mathrm{~h}$ e às $22 \mathrm{~h}$, durante o período de 09 de agosto de 2017 a 22 de novembro de 2017, foram utilizados para da por meio da transpiração, podendo contribuir com até $40 \%$ da capacidade de um telhado verde de reter a água pluvial, dependendo da quantidade de chuva.

Em razão do porte rasteiro, do bom desenvolvimento e da ramificação, além do baixo consumo hídrico, essa espécie vegetal foi cultivada nos três sistemas instalados, com as mesmas características de espaçamento, fornecimento de água pelo sistema de irrigação e data de realização do plantio.

ções e instalados os gotejadores, os quais têm a função de liberar a água ao substrato, de acordo com a necessidade hídrica.

O controle do sistema de irrigação foi realizado por um timer, ajustando-se o tempo em que o sistema deve funcionar e a frequência. Três timers foram instalados, um para cada protótipo. Para o desenvolvimento inicial da espécie, o ajuste foi realizado para que o funcionamento ocorresse a cada seis horas, por cinco minutos em cada turno de rega. A vazão do sistema variou entre 2 e $3 \mathrm{~L} \mathrm{~h}^{-1}$. Depois do primeiro mês, com a vegetação já estabelecida, foi realizado o ajuste de funcionamento para cinco minutos a cada doze horas.

ma. Dessa forma, pôde-se avaliar a variação de temperatura em ${ }^{\circ} \mathrm{C}$, entre as partes externa (incidência solar) e interna.

O sistema de coleta e transmissão de dados possibilitou que as diversas coletas realizadas fossem enviadas diretamente para o servidor local, via Wi-Fi.

O sensor de temperatura utilizado para as coletas iniciais foi o DS18B20, dispositivo capaz de medir a temperatura do local em que está disposto, fornecendo valores para cada temperatura medida. Tem como característica a praticidade, por ser à prova d'água e suportar as diversas condições climatológicas (STEIDLE, 2005).

analisar a atenuação da temperatura, pelos diferentes sistemas de telhados verdes, comparando os resultados dos diferentes sistemas com os da testemunha. 
Considerou-se, para análise dos dados, o limite superior de conforto térmico (LSCT), segundo a NBR $16401 / 08$, para o verão: $26^{\circ} \mathrm{C}$. Em relação ao limite inferior de conforto térmico (LICT), utilizou-se a menor temperatura da norma de referência, observada no inverno: $21^{\circ} \mathrm{C}$.

As diferenças entre as temperaturas externa e interna foram utilizadas para averiguar a atenuação da radiação solar, evidenciando o potencial de isolamento térmico dos telhados verdes. Esses resultados foram submetidos a teste estatístico, comparando-se as médias das diferenças de temperaturas dos 85 dias coletados.
Aplicou-se uma constante no valor de 100 nas diferenças de temperatura, para serem possíveis as análises estatísticas.

No experimento foi adotado o delineamento de blocos ao acaso, no esquema fatorial $4 \times 2$, no qual são empregados quatro protótipos em dois horários analisados.

As análises estatísticas foram realizadas no programa Statistical Analysis System (SAS), por meio do teste F da análise de variância, para verificar a hipótese de que as médias são estatisticamente iguais ou diferem entre si. O teste de Tukey a $5 \%$ de significância foi aplicado para comparação das médias dos tratamentos.

\section{RESULTADOS E DISCUSSÃO}

\section{Conforto térmico}

Em relação às temperaturas internas dos protótipos para análise do conforto térmico, duas principais situações são válidas a se observar: em relação ao calor interno excessivo provocado pela radiação solar (principalmente nos horários mais quentes); e em relação a todo o calor armazenado durante o dia (emitido novamente ao ambiente, devido às diferenças de temperatura externa).

Além disso, a diferença entre as temperaturas internas e externas também são importantes na avaliação do potencial de isolamento térmico de coberturas vegetais.

Nos horários mais quentes do dia, como às $13 \mathrm{~h}$, o potencial do telhado verde, principalmente em relação à testemunha, pode ser mais bem observado (Figura 3).

As temperaturas internas registradas no protótipo testemunha são muito elevadas, principalmente porque o calor, quando não há telhado verde, é mais facilmente transmitido para o compartimento abaixo (no qual se localiza o sensor), aumentando a temperatura interna. Esse resultado evidencia a eficiência do telhado verde no isolamento térmico de um ambiente.

No caso dos protótipos que têm o telhado verde instalado, apesar de a temperatura ficar acima da zona de conforto térmico, em alguns períodos, a diferença em relação ao protótipo testemunha é grande.

Do total dos 255 dados analisados às $13 \mathrm{~h}$ para os 3 sistemas com cobertura vegetal, apenas $40 \%$ ficaram na zona de conforto térmico ao longo do período, entretanto os valores de temperatura interna são expressivamente menores, chegando a $43 \%$ de redução no sistema com telhado verde em relação ao protótipo testemunha.

Segundo Liu e Baskaran (2003), a cobertura verde reduz em $95 \%$ o ganho de calor em horários mais quentes do dia. Além disso, a amplitude térmica é significativamente reduzida e, ainda, a demanda de energia gasta com ar-condicionado é reduzida em $25 \%$.

Na semana de 16 a 23 de agosto, de acordo com os dados da estação meteorológica, as temperaturas externas são amenas, a radiação é baixa e a pluviosidade é alta, em relação ao período todo. Dessa forma, o potencial de isolamento térmico do telhado verde não é tão representativo.

Já nos casos de altas temperaturas, como no dia 14 de outubro, têm-se temperatura externa de $35,4^{\circ} \mathrm{C}$ e radiação de $834,17 \mathrm{Wm}^{-2}$, enquanto a temperatura interna do protótipo testemunha é de $54,7^{\circ} \mathrm{C}$. Para os protótipos com telhados verdes, a temperatura interna ficou entre 31,0 e $33,9^{\circ} \mathrm{C}$. Sendo assim, ainda que as temperaturas estejam acima da zona de conforto térmico, a diferença em relação ao sistema testemunha é de $23,0^{\circ} \mathrm{C}$, uma redução máxima de $43 \%$.

De acordo com Koenigsberger et al. (1980), a temperatura normal da pele varia entre 31 e $34^{\circ} \mathrm{C}$. Em todo o período avaliado, a maior temperatura interna encontra- 
da nos protótipos com cobertura vegetal foi de $33,9^{\circ} \mathrm{C}$. Dessa forma, o organismo humano não vai trocar calor com o ambiente de forma significativa, já que o valor está abaixo do limite da temperatura normal da pele.

A vegetação auxiliou para a ocorrência de maior conforto térmico, uma vez que grande quantidade de radiação solar é absorvida pela vegetação, que apresentou bom desenvolvimento nos telhados verdes instalados. Essa radiação não é transmitida para as outras camadas, como o substrato e as diferentes estruturas dos sistemas de telhados verdes. Segundo Theodosiou (2003), a densidade das folhagens influencia o desempenho térmico dos telhados verdes, uma vez que possibilita maior sombreamento e evapotranspiração. Para Del Barrio (1998), a importância da vegetação está relacionada à distribuição horizontal das folhas, proporcionando menor transmissão de radiação solar para a superfície do substrato, sendo que as trocas de ar entre a camada vegetal e o ar externo do telhado verde desempenham importante papel para o estado higrotérmico.

O substrato também tem papel importante na retenção do calor. Seu principal efeito está relacionado à espessura, uma vez que há uma atenuação no fluxo de calor recebido externamente pela radiação solar. Portanto, o fluxo de calor é diretamente proporcional à espessura do substrato, sendo que, quanto maior a espessura do substrato, maior a inércia térmica e menor o fluxo de calor, tanto de fora para dentro quanto de dentro para fora (THEODOSIOU, 2003).

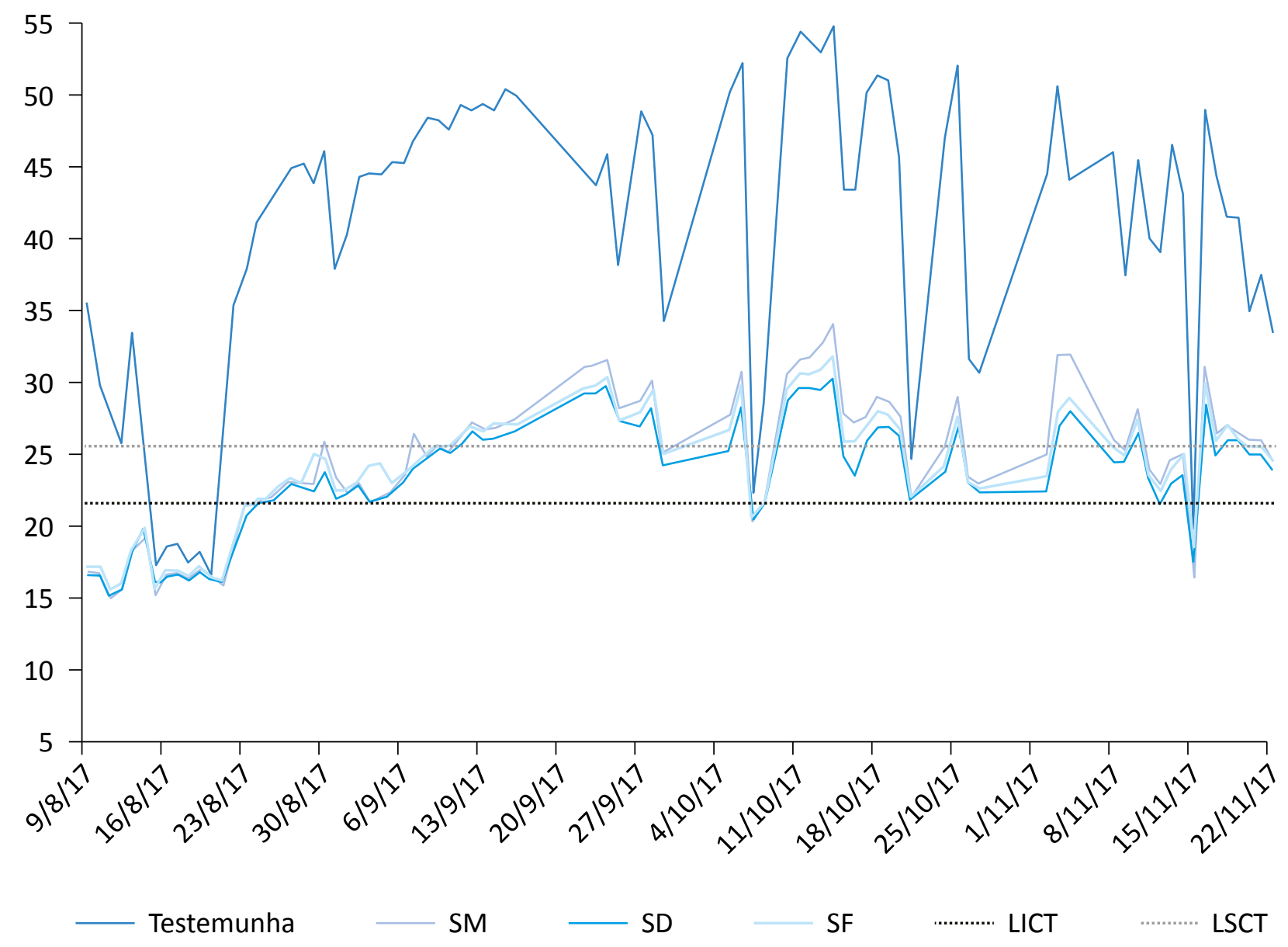

SM: Sistema Modular; SD: Sistema MacDrain; SF: Sistema FLAT; LICT: limite inferior de conforto térmico; LSCT: limite superior de conforto térmico.

Figura 3 - Gráfico de temperatura interna às $13 \mathrm{~h} 00$ em relação aos limites inferior e superior de conforto térmico, respectivamente, nos Sistemas Modular, MacDrain, FLAT e Testemunha. 
Por meio de análises térmicas realizadas em Sidney e no Rio de Janeiro, Wilkinson et al. (2017) comprovaram o potencial de telhados verdes e jardins verticais para a atenuação da temperatura em experimento com estruturas fechadas de madeira, com e sem coberturas verdes, e jardins verticais. As temperaturas chegaram a $6^{\circ} \mathrm{C}$ de diferença, devido ao aumento do isolamento térmico da estrutura pelos sistemas verdes instalados.

No caso de temperaturas amenas, como no período noturno, telhados verdes reduzem em $26 \%$ a perda do calor, proporcionando maior conforto térmico (LIU \& BASKARAN, 2003). Esse efeito pode ser comprovado na Figura 4.

As temperaturas mais amenas dos sensores abaixo dos sistemas são decorrentes do calor retido no com- partimento durante o dia (mantido pelos sistemas de telhados verdes), diferente do protótipo testemunha, que, por não possuir nenhum sistema instalado, tende a perder calor e manter a temperatura interna mais baixa.

A maior parte das temperaturas coletadas às $22 \mathrm{~h}$ manteve-se abaixo do limite superior de conforto térmico, $26,0^{\circ} \mathrm{C}$, e dentro da faixa considerada ideal, demonstrando a eficiência do sistema no período noturno.

Em noites de inverno com temperaturas baixas, como no caso do dia 21 de agosto, os sistemas de telhado verde conseguiram manter as temperaturas internas mais próximas do limite inferior de conforto térmico. Sendo assim, foi possível manter o ambiente mais agradável, uma vez que apresentou temperatura interna de $12,5^{\circ} \mathrm{C}$ dos protóti-



SM: Sistema Modular; SD: Sistema MacDrain; SF: Sistema FLAT; LICT: limite inferior de conforto térmico; LSCT: limite superior de conforto térmico.

Figura 4 - Gráfico de temperatura interna às $22 \mathrm{~h} 00$ em relação aos limites inferior e superior de conforto térmico, respectivamente, nos Sistemas Modular, MacDrain, FLAT e Testemunha. 
pos com telhado verde, a mesma temperatura do ambiente externo, enquanto o protótipo testemunha registrou $8,6^{\circ} \mathrm{C}$.

De acordo com Vieira et al. (2016), em pesquisas realizadas com coberturas de telhado de fibrocimento comparado ao telhado verde sobre a estrutura de fibrocimento, o fluxo de calor no período noturno é invertido, passando a ser do interior do cômodo para o telhado; dessa forma, durante a noite as temperaturas no cômodo com telhado verde estavam maiores do que no local com somente a telha de fibrocimento.

Em trabalhos realizados por Vecchia (2005) e Vacilikio e Fleiscfresser (2011), foi demonstrado que telhados verdes reduziram as temperaturas durante o

\section{Comparação dos sistemas}

As médias das diferenças entre os valores de temperatura do ar (externo e interno) foram comparadas estatisticamente.

Esses valores encontrados são provenientes das diferenças do comportamento térmico dos diferentes sistemas que compõem os protótipos instalados.

Às $13 \mathrm{~h}$, o menor valor da média das diferenças de temperatura do protótipo testemunha representa que a temperatura externa é menor que a temperatura interna, devido a maior transmissão de calor para o compartimento, resultante da ausência do sistema de telhado verde.

Pode-se observar, na Tabela 1, que o Sistema FLAT difere do Sistema Modular, apresentando efeitos diferentes no potencial de isolamento térmico desses tipos de telhados verdes. A maior diferença de temperatura externa em relação à temperatura interna no Sistema FLAT che- dia e conseguiram retardar o resfriamento durante a noite.

Da mesma forma que a transferência de calor durante o dia é menor no sentido do ambiente externo para o interior dos compartimentos dos protótipos, as camadas que compõem os diferentes sistemas de telhados verdes são responsáveis também por reter o calor, que tende a se dissipar no período noturno, em que as temperaturas externas são menores e não há o fenômeno da radiação solar.

Apesar de os dados de temperatura interna não ficarem na zona de conforto térmico, em relação à testemunha, os valores ficam mais próximos do limite inferior proposto pela norma.

gou a $16^{\circ} \mathrm{C}$ em todos os dias analisados; já no caso do Sistema Modular, a maior diferença foi de $12,3^{\circ} \mathrm{C}$.

A amplitude térmica chegou a $-18,8^{\circ} \mathrm{C}$ no caso do protótipo testemunha, no dia 17 de outubro. Enquanto a temperatura externa era de $31,25^{\circ} \mathrm{C}$ e a radiação de 871 $\mathrm{Wm}^{-2}$, o sensor interno indicava $50,1^{\circ} \mathrm{C}$. O valor negativo indica a temperatura interna maior que a externa do ar.

Em trabalho realizado por Panziera et al. (2015), a temperatura interna de um ambiente com telhado convencional de fibrocimento foi estatisticamente diferente de um local com telhado verde nos horários mais quentes do dia, o que comprova que o sistema de cobertura vegetal foi eficaz na redução do ganho de calor do ambiente.

Para o horário de medição noturna, o protótipo testemunha foi o único a diferir estatisticamente do restante dos dados, conforme a Tabela 2, evidenciando o

Tabela 1 - Comparação entre os sistemas às 13h.

\section{Tratamento}

Sistema FLAT

Sistema MacDrain

Sistema Modular

Testemunha

\section{Médias}

107,13 a

$106,93 \mathrm{ab}$

$106,00 \mathrm{~b}$

89,91 c

Letras iguais na mesma coluna não diferem entre si pelo teste de Tukey a 5\%. 
Tabela 2 - Comparação entre os sistemas às $\mathbf{2 2 h}$.

Tratamento

Testemunha

Sistema Modular

Sistema MacDrain

Sistema FLAT

\section{Médias}

102,12 a

98,47 b

98,38 b

97,52 b

Letras iguais na mesma coluna não diferem entre si pelo teste de Tukey a $5 \%$.

efeito negativo da ausência do sistema de telhado verde à noite, que possibilitaria maior dissipação do calor acumulado nos compartimentos durante o dia.

A média das diferenças no caso da testemunha foi de $2,12^{\circ} \mathrm{C}$, indicando que a temperatura externa ao protótipo é maior que a interna e, dessa forma, o ambiente interno é mais frio. No caso das outras médias dos protótipos que têm cobertura vegetal, os valores foram negativos, apontando a temperatura interna maior que a externa e, dessa forma, contribuindo para o conforto térmico. A diferença entre as médias dos diferentes sistemas não foi estatisticamente significante.

\section{CONCLUSÕES}

O telhado verde é efetivo na atenuação da radiação incidente na cobertura, resultando em menores temperaturas internas em horários mais quentes; em períodos mais frios, como à noite, tem a capacidade de manter a temperatura interna maior que a externa. Comparando-se com o protótipo apenas impermeabilizado, sem cobertura vegetal, todos os sistemas de teIhados verdes instalados foram efetivos para o conforto térmico, uma vez que as camadas que compõem os protótipos são responsáveis pela menor transmissão de calor entre os ambientes externo e interno. Nos dois horários avaliados o sistema foi efetivo, e a maior diferença observada entre um protótipo com e sem telhado verde foi de $23,0^{\circ} \mathrm{C}$, às $13 \mathrm{~h}$, em razão da maior temperatura externa e da radiação. Mesmo em dias mais frios, como foi observado no inverno, o sistema de cobertura vegetal foi eficaz em manter as temperaturas mais agradáveis e próximas da zona de conforto térmico, conservando o calor armazenado durante o dia no interior do compartimento. Levando em conta que a temperatura da pele humana possui variação que vai de 31 a $34^{\circ} \mathrm{C}$, às $13 \mathrm{~h}$, todos os sistemas de cobertura vegetal mantiveram a temperatura interna menor que o limite superior de $34^{\circ} \mathrm{C}$. Dessa forma, conclui-se que a utilização da vegetação sobre as edificações apresentou bom comportamento térmico em relação às variações térmicas externas, principalmente se comparada a uma cobertura convencional, apenas impermeabilizada. Para cada local com o sistema instalado, um tipo de vegetação adaptada pode ser utilizado, o que comprova todas as vantagens em relação ao telhado verde, contribuindo para o aumento das áreas verdes nos grandes centros urbanos.

\section{REFERÊNCIAS}

ALAMY FILHO, J. E.; MANNA, I. B. C. B.; MELO, N. A.; CAIXETA, A. C. M. Hydrological efficiency of green roofs for residential neighborhoods scale. Sociedade \& Natureza, v. 28, n. 2, p. 257-272, 2016. http://dx.doi.org/10.1590/1982451320160206

ASSOCIAÇÃO BRASILEIRA DE NORMAS TÉCNICAS (ABNT). NBR 16401: Instalações de ar condicionado: sistemas centrais e unitários. Rio de Janeiro: ABNT; 2008. 
BARROS, H. R.; LOMBARDO, M. A. A ilha de calor urbana e o uso e cobertura do solo em São Paulo-SP. GEOUSP: Espaço e Tempo, v. 20, n. 1, p. 160-177, 2016. https://doi.org/10.11606/issn.2179-0892.geousp.2016.97783

BERGHAGE, R.; JARRETT, A.; BEATTLE, D.; KELLEY, K.; HUSAIN, S.; REZAI, F.; LONG, B.; NEGASSI, A.; CAMERON, R.; HUNT, W. Quantifying evaporation and transpirational water losses from green roofs and green roof media capacity for neutralizing acid rain. National Decentralized Water Resources Capacity Development Project. Pennsylvania: Pennsylvania State University; 2007.

BEZERRA M. I. L.; SANTOS, J. S.; AGUIAR, A. P. Ilhas de Calor: Importância da Vegetação na Amenização Climática em João Pessoa\PB. Revista Brasileira de Geografia Física, v. 6, n. 5, p. 1499-1516, 2013.

CLIMA SOROCABA. Sorocaba: Climate-data. Disponível em: <https://pt.climate-data.org/america-do-sul/brasil/saopaulo/sorocaba-756>. Acesso em: 04 dez. 2018.

DEL BARRIO, E. P. Analysis of the green roofs cooling potential in buildings. Energy and Buildings, v. 27, n. 2, p. 179-193, 1998. https://doi.org/10.1016/S0378-7788(97)00029-7

GALLARDO, P. N.; ROGÉRIO, A.; NEVES, G. Z. F.; VECCHIA, F. A.; RORIZ, V. F. Thermal response to cold in buildings with green covers for tropical climate. Green facades and green roofs. Revista Ingeniería de Construcción, v. 33, n. 1, p. 15-28, 2018. http://dx.doi.org/10.4067/S0718-50732018000100015

GENGO, R. C.; HENKES, J. A. A utilização do paisagismo como ferramenta na preservação e melhoria ambiental em área urbana. Revista Gestão \& Sustentabilidade Ambiental, v. 1, n. 2, p. 55-81, 2012. http://dx.doi.org/10.19177/rgsa. v1e2201255-81

HASHEMI, S. S. G.; MAHMUD, H. B.; ASHRAF, M. A. Performance of green roofs with respect to water quality and reduction of energy consumption in tropics: a review. Renewable and Sustainable Energy Reviews, v. 52, p. 669-679, 2015. http://dx.doi.org/10.1016/j.rser.2015.07.163

HIEN, W. N.; YOK, T. P.; YU, C. Study of Thermal Performance of Extensive Rooftop Greenery Systems in the Tropical Climate. Journal of Building and Environment, Amsterdã, v. 42, n. 1, p. 25-54, 2007.

INFORMAÇÕES SOROCABA. Sorocaba: DBcity.com. Disponível em: <https://pt.db-city.com/Brasil--S\%C3\%A3o-Paulo-Sorocaba>. Acesso em: 04 dez. 2018.

KOENIGSBERGER, O. H.; INGERSOLL, T. G.; MAYHEW, A.; SZOKOLAY, S. V. Manual of tropic housing and building: climatic design. Londres: Longman, 1980. v. 1. 320 p.

KREITH, F.; MANGLIK, R. M.; BOHN, M. S. Princípios de transferência de calor. 7. ed. São Paulo: Cengage Learning, 2014.

LEHMANN, S.; CROCKER, R. (Orgs.). Designing for zero waste: consumption, technologies and the built environment. Reino Unido: Routledge, 2013.

LIMA, S. M.; GARCEZ, D. S. Áreas verdes públicas urbanas e sua relação com a melhoria da qualidade de vida: um estudo de caso em um parque ecológico urbano na cidade de Fortaleza (Ceará, Brasil). Revista Brasileira de Ciências Ambientais, n. 43, p. 140-151, 2017. http://dx.doi.org/10.5327/Z2176-947820170126

LIU, K.; BASKARAN, B. Thermal performance of green roofs through field evaluation. In: NORTH AMERICAN GREEN ROOF INFRASTRUCTURE CONFERENCE, AWARDS AND TRADE SHOW, 1., 2003. Proceedings... 2003. p. 29-30.

MINKS, V. A rede de design verde urbano - uma alternativa sustentável para megacidades? Revista LABVERDE, n. 7, p. 120-141, 2013. https://doi.org/10.11606/issn.2179-2275.v0i7p120-141

MOAVENI, S. Fundamentos de engenharia: uma introdução. São Paulo: Cengage Learning, 2016. 
NIACHOU, A.; PAPAKONSTANTINOU, K.; SANTAMOURIS, M.; TSANGRASSOULIS, A.; MIHALAKAKOU, G. Analysis of green roof thermal properties and investigation of its energy performance. Energy and Buildings, v. 33, n. 7, p. 719-729, 2001. https://doi.org/10.1016/S0378-7788(01)00062-7

OLIVEIRA, N. W. E. Telhados verdes para habitações de interesse social: retenção das águas pluviais e conforto térmico. Dissertação (Mestrado em Saneamento Ambiental) - Universidade do Estado de Rio de Janeiro, Rio de Janeiro, 2009.

ONMURA, S.; MATSUMOTO, M.; HOKOI, S. Study on evaporative cooling effect of roof lawn gardens. Energy and Buildings, v. 33, n. 7, p. 653-666, 2001. http://dx.doi.org/10.1016/S0378-7788(00)00134-1

PANZIERA, A. G.; CALIL, V. S.; AMARAL, F. D.; SWAROWSKY, A. Desempenho de diferentes tipos de telhado verde no conforto térmico urbano na cidade de Santa Maria, RS. Disciplinarum Scientia/ Naturais e Tecnológicas, v. 16, n. 3, p. 445-457, 2015.

PRAMANIK, M. A.; STATHAKIS, D. Forecasting urban sprawl in Dhaka city of Bangladesh. Environment and Planning B: Planning and Design, v. 43, n. 4, p. 756-771, 2016. https://doi.org/10.1177\%2F0265813515595406

RANGEL, A. C. L. C.; ARANHA, K. C.; SILVA, M. C. B. C. Os telhados verdes nas políticas ambientais como medida indutora para a sustentabilidade. Desenvolvimento e Meio Ambiente, v. 35, p. 397-409, 2015. http://dx.doi.org/10.5380/dma. v35i0.39177

RODRIGUES, A. M.; PIEDADE, A. C.; BRAGA, A. M. Térmica de edifícios. Amadora: Orion, 2009.

SAADATIAN, O.; SOPIAN, K. B.; SALLEH, E.; LIM, C. H.; RIFFAT, S.; SAADATIAN, E.; TOUDESHKI, A.; SULAIMAN, Y. A review of energy aspects of green roofs. Renewable and Sustainable Energy Reviews, v. 23, p. 155-168, 2013. http://dx.doi. org/10.1016/j.rser.2013.02.022

SANTAMOURIS, M. Cooling the cities-a review of reflective and green roof mitigation technologies to fight heat island and improve comfort in urban environments. Solar Energy, v. 103, p. 682-703, 2014. http://dx.doi.org/10.1016/j. solener.2012.07.003

SOUZA, V. C.; LORENZI, H. Botânica sistemática. Nova Odessa: Instituto Plantarum, 2005.

STEIDLE NETO, A. J.; BAÊTA, F. C.; MARTINS, J. H.; ZOLNIER, S.; MONTEIRO, P. M. B. Avaliação da transmissão de dados de temperatura no Sistema 1-wire. Engenharia Agrícola, v. 25, n. 1, p. 29-36, 2005.

STUMPF, M. A planta rasteira dinheiro-em-penca: Ficha técnica Callisia repens. Disponível em: <www.fazfacil.com.br/ jardim/forracoes_dinheiro_em_penca.html>. Acesso em: 12 dez. 2017.

SUTTON, R. K. Introduction to green roof ecosystems. In: Green Roof Ecosystems. Nova York: Springer, 2015. p. 1-25.

TAM, V. W. Y.; WANG, J.; LE, K. N. Thermal insulation and cost effectiveness of green-roof systems: An empirical study in Hong Kong. Building and Environment, v. 110, p. 46-54, 2016. http://dx.doi.org/10.1016/j.buildenv.2016.09.032

TEIXEIRA, C. A.; BUDEL, M. A.; CARVALHO, K. Q.; BEZERRA, S. M. C.; GHISI, E. Estudo comparativo da qualidade da água da chuva coletada em telhado com telhas de concreto e em telhado verde para usos não potáveis. Ambiente Construído, v. 17, n. 2, p. 135-155, 2017. http://dx.doi.org/10.1590/s1678-86212017000200150

THEODOSIOU, T. G. Summer period analysis of the performance of a planted roof as a passive cooling technique. Energy and Buildings, v. 35, n. 9, p. 909-917, 2003. https://doi.org/10.1016/S0378-7788(03)00023-9 
VACILIKIO, D. V.; FLEISCFRESSER, L. Comparação entre telhado verde e convencional nas temperaturas internas de ambientes. In: SIMPÓSIO AMBIENTAL DA UNIVERSIDADE TECNOLÓGICA FEDERAL DO PARANÁ, 2., 2011. Anais... v. 3, 2011.

VECCHIA, F. Cobertura verde leve (CVL): ensaio experimental. In: ENCONTRO NACIONAL DE CONFORTO NO AMBIENTE CONSTRUÍDO, 6.; ENCONTRO LATINO-AMERICANO SOBRE CONFORTO NO AMBIENTE CONSTRUÍDO, 4., 2005, Maceió. Anais... Maceió, 2005.

VIEIRA, T. J.; FLEISCHFRESSER, L.; PRUDENTE, L. A. Comparação da variação de temperatura interna de um ambiente revestido com telhado verde e um com telhado convencional. In: ENCONTRO NACIONAL DOS ESTUDANTES DE ENGENHARIA AMBIENTAL; FÓRUM LATINO AMERICANO DE ENGENHARIA E SUSTENTABILIDADE; SIMPÓSIO BRASILEIRO DE ENGENHARIA AMBIENTAL-CENTRO-OESTE, 2016. Anais... 2016.

VIJAYARAGHAVAN, K. Green roofs: A critical review on the role of components, benefits, limitations and trends. Renewable and Sustainable Energy Reviews, v. 57, p. 740-752, 2016. http://dx.doi.org/10.1016/j.rser.2015.12.119

VIJAYARAGHAVAN, K.; JOSHI, U. M. Application of seaweed as substrate additive in green roofs: Enhancement of water retention and sorption capacity. Landscape and Urban Planning, v. 143, p. 25-32, 2015. http://dx.doi.org/10.1016/j. landurbplan.2015.06.006

WILKINSON, S.; FEITOSA, R. C.; KAGA, I. T.; FRANCESCHI, I. H. Evaluating the thermal performance of retrofitted lightweight green roofs and walls in Sydney and Rio de Janeiro. Procedia Engineering, v. 180, p. 231-240, 2017. https:// doi.org/10.1016/j.proeng.2017.04.182

WONG, N. H.; CHEN, Y.; ONG, C. L.; SIA, A. Investigation of thermal benefits of rooftop garden in the tropical environment. Building and Environment, v. 38, n. 2, p. 261-270, 2003. http://dx.doi.org/10.1016/S0360-1323(02)00066-5

YANG, H. S.; KANG, J.; CHOI, M. S. Acoustic effects of green roof systems on a low-profiled structure at street level. Building and Environment, v. 50, p. 44-55, 2012. http://dx.doi.org/10.1016/j.buildenv.2011.10.004 